\section{Astaksantin'in kimyası ve uygulamaları üzerine bir inceleme}

\section{A review of astaxantine's chemistry and its applications}

\section{ÖZET}

Doğal bir antioksidan olan Astaksantin Su ürünleri yetiştiriciliğinde, ete pembe renk özelliğini sağlamak için alabalık ve kabuklu su ürünleri üretiminde yaygın olarak kullanılan bir karotenoiddir. Bu uygulama doksanlı yıllardan bu yana otuz yılı aşkın bir süredir kullanılmakla birlikte günümüzde gıda renk maddeleri endüstrisinde en önemli pigmentlerden biridir. Ek olarak, astaksantin balıkların üreme süreçlerinde yumurta ve sperm kalitesinin artmasında önemli bir rol oynamaktadır. Dünya pazarına ağırlıklı olarak sentetik astaksantin kullanımı hâkim olmakla birlikte, pigmentin doğal kaynaklarına olan ilgi son zamanlarda büyük ölçüde artmıştır. Doğal astaksantinin en yaygın kaynakları kabuklu yan ürünlerinin yanı sıra yeşil alglerden Haematococcus pluvialis, kırmızı maya Phaffia rhodozyma'dır. Astaksantin, kapsüllenmiş ürün olarak nutrasötik pazarında talep artışına sahip olan bir antioksidandır. Ayrıca, astaksantinin tüketiminin kardiyovasküler hastalıkların önlenmesi, bağışıklık sisteminin güçlendirilmesi, Helycobacter pylori'ye karşı biyoaktivite ve kataraktın önlenmesi gibi insan sağlığı yönünden birçok yararı olduğu bildirilmektedir. Bu makale, astaksantin pigmentinin kimyası ve canlılar üzerine potansiyel yararlı etkileri ile ilgili mevcut kanıtları gözden geçirmektedir.

Anahtar Kelimeler: Astaksantin, antioksidanlar, karotenoidler

\section{ABSTRACT}

Astaxanthin, a natural antioxidant, is a carotenoid widely used in aquaculture, in the production of trout and shellfish to provide the pink color of meat. Although this application has been used for over thirty years since the nineties, it is one of the most important pigments for food colouring industry today. Additionally, astaxanthin plays an important role in improving egg and sperm quality in fish reproductive processes. The world market is dominated by the use of synthetic astaxanthin, besides, interest in natural sources of the pigment has grown considerably recently. The most common sources of natural astaxanthin are the green algae Haematococcus pluvialis, the red yeast Phaffia rhodozyma, as well as crustacean byproducts. Astaxanthin is an antioxidant that has increased demand in the nutraceutical market as an encapsulated product. In addition, the consumption of astaxanthin has many health benefits, such as the prevention of cardiovascular diseases, strengthening the immune system, bioactivity against Helycobacter pylori, and prevention of cataracts. This article reviews the available evidence on astaxanthin chemistry and its potential beneficial effects on living things.

Keywords: Astaxanhin, antioxidants, carotenoids
Review Article

Çiğdem Dikel

Cukurova University, Adana, Turkey

ORCID-

$\underline{0000-0002-5533-8899}$

Correspondence

Çiğdem DİKEL

atlasdike101@gmail.com

Article info

Submission: 28-06-2021

Accepted: 07-12-2021

e-ISSN : 2548-1150

doi prefix: $10.31797 /$ vetbio

- http://dergipark.org.tr/vetbio 


\section{İRIŞ

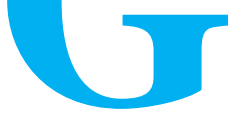 \\ Son on y1lda, deniz organizmalarında ilginç} farmasötik aktivitelere sahip çok sayıda madde tanımlanmıştır. Deniz ortamlarının çeşitliliği, önemli bir biyoaktif bileşik kaynağı sağlamaktadır. Bu, hücresel redoks durumu değişiklikleri ile karakterize edilen birçok hastalığa karşı terapötik stratejide etkinlik ve düşük toksisite ile doğal kaynaklı potansiyel yeni ilaç adaylarına yol göstermektedir. Doğal antioksidan maddeler aracılığıyla beslenme yaklaşımı, kardiyovasküler hastalıkların hem önlenmesinde hem de tedavisinde önemli bir yeni çizgiyi temsil eder. Bilimsel kanıtlar, bazı inflamatuar ve kronik hastalıklara karşı fitokimyasalların yararlı rollerini desteklemektedir. Doğal olarak oluşan birkaç antioksidan biyoaktif madde, bunların önlenmesi ile ilişkilendirilmiştir (Gammone vd., 2015).

Büyük antioksidan özelliklere sahip birçok karotenoid, hem epidemiyolojik çalışmalarda hem de insanlarda besin takviyesi denemelerinde bir risk azalması sergilemiş, bu da oksidatif stres, proinflamatuar bir sistemik ortam ve çok sayıda kronik hastalık arasında güçlü bir bağlantının varlığını göstermiştir (D’Orazio, vd., 2012). Sonuç olarak, beslenme iyileştirmesi, insan sağlığını daha iyi bir yaşam kalitesi kadar morbidite ve mortalitenin azalmasına doğru kaydırabilmektedir.

Astaksantin, tetraterpenoidler olarak bilinen fitokimyasallar sinıfina ait olan ve sekiz izopren, $\mathrm{C}_{5} \mathrm{H}_{8}$ molekülünden oluşan bir karotenoiddir; ilk öncü olarak izopentenil difosfat (veya IPP) ve dimetilalil difosfattır (veya DMAPP) (Şekil 1). Birçok karotenoid gibi, astaksantin renkli ve lipitte çözünürlüğe sahip pigmenttir. Astaksantinin rengi, bileşiğin merkezindeki genişletilmiş konjuge (dönüşümlü çift ve tek) çift bağ zincirinden kaynaklanmaktadır (Choi vd., 2005).

$\mathrm{Bu}$ karotenoidler sadece harika doğal renkler sağlamakla kalmaz, aynı zamanda oksidatif stresi hafifletmek için antioksidan olarak biyolojik açıdan önemli rol oynamaktadır (Krinsky 1994).

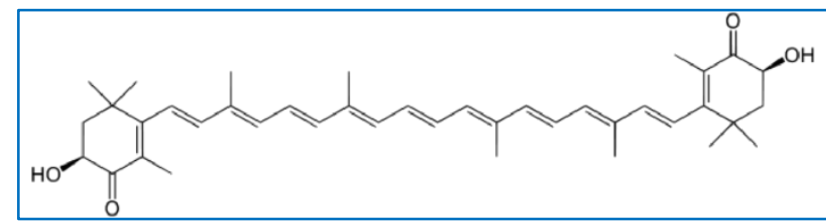

Şekil 1. Astaksantinin Moleküler yapısı (Gammone vd., 2015)

Olağanüstü antioksidan aktivitesi nedeniyle Astaksantin, organizmayı kardiyovasküler problemler, farklı kanser türleri ve bazı immünolojik sistem hastalıkları gibi çeşitli rahatsızlıklara karşı korumak için üstün bir potansiyele sahiptir. Bu dikkat çekici özellikler, Astaksantin'e büyük ilgi uyandırarak insanlara ve hayvanlara potansiyel faydaları ile ilgili çok sayıda araştırma yapılmasına yol açmaktadır. Günümüzde dünya pazarlarının çoğunu kapsayan sentetik pigmente alternatif olarak doğal Astaksantin kaynaklarının (alg, maya ve kabuklu yan ürünleri) tanımlanması, üretimi ve kullanımına da odaklanılmaktadır. Bu derleme, bu doğal bileşenin önemine dair güncellenmiş çalışmalara, genel bir bakış açısı sağlamayı amaçlamaktadır.

\section{ASTAKSANTIN KAYNAKLARI}

\section{Sentetik astaksantin}

Sentetik Astaksantin, canlı organizmalarda üretilenle aynı moleküldür ve sırasıyla 1: 2: 1 izomer $\left(3 \mathrm{~S}, 3 \mathrm{~S}^{\prime}\right),\left(3 \mathrm{R}, 3 \mathrm{~S}{ }^{\prime}\right)$ ve $(3 \mathrm{R}, 3 \mathrm{R})$ karışımından oluşmaktadır. $\mathrm{Su}$ ürünleri yetiştiriciliği endüstrisinde dünya çapında kullanılan ana karotenoiddir. Roche firmas1, 1990 yılında büyük ölçekli sentetik Astaksantin üretimine başladı ve Astaksantin pigmentin dünya pazarındaki değerinin 150-200 milyon 
dolar olduğu tahmin edilmektedir. Bununla birlikte, doğal gidalara talebin artması ve sentetik pigmentlerin yüksek maliyeti, sanayileşme potansiyeli olan doğal Astaksantin kaynaklarına yönelimi teşvik etmektedir.

\section{Astaksantin'in doğal kaynakları}

Astaksantinin doğal kaynakları yosun, maya, somon, mollusk, alabalık, kril, karides ve kerevittir (Catanzaro vd., 2020). Çeşitli mikroorganizma kaynaklarından elde edilen astaksantin, Tablo 1. de verilmiştir. Ticari astaksantin esas olarak Phaffia mayas1, Haematococcus'tan ve kimyasal sentez yoluyla elde edilir. Haematococcus pluvialis, doğal astaksantinin en iyi kaynaklarından biridir (Lorenz 1999; EFSA 2005; Ranga Rao vd., 2009; Ranga Rao vd., 2010).

Doğadaki ve çiftlik alabalıklarındaki astaksantin içeriği Şekil 1'de verilmiştir. Yabani salmonidler arasında, yabani Oncorhynchus türlerindeki maksimum astaksantin içeriği, sockeye salmonunda $26-38 \mathrm{mg} / \mathrm{kg}$ et aralığında bildirilirken, düşük astaksantin içeriği chum salmonunda bildirilmiştir (EFSA 2005). Yetiştirilmiş Atlantik salmonundaki astaksantin içeriği 6-8 mg / $\mathrm{kg}$ et olarak rapor edilmiştir. Astaksantin, Avrupa alabalıklarda (6 mg / kg et) ve Japon pazarındaki alabalıklarda $(25 \mathrm{mg} / \mathrm{kg}$ et) mevcuttur. Karides, yengeç ve somon, astaksantin için diyet kaynakları olarak hizmet edebilir (EFSA 2005). Doğadan yakalanmış somon, iyi bir astaksantin kaynağıdır. 3,6 mg astaksantin elde etmek için günde 165 gram somon balığı tüketilebilir. Günde $3,6 \mathrm{mg}$ Astaksantin takviyesi, Iwamoto $v d$., tarafindan bildirildiği gibi sağlığa faydalı olabilmektedir (Iwamoto vd., 2000).

Tablo 1. Mikroorganizmaların Astaksantin içerikleri

\begin{tabular}{|l|c|}
\hline \multicolumn{1}{|c|}{ Astaksantin Kaynakları } & $\begin{array}{c}\text { Kuru ağırlıta } \\
\text { Astaksantin (\%) }\end{array}$ \\
\hline Chlorophyceae & 3,8 \\
\hline Haematococcus pluvialis & 3,8 \\
\hline $\begin{array}{l}\text { Haematococcus pluvialis (K- } \\
\text { 0084) }\end{array}$ & 3,6 \\
\hline $\begin{array}{l}\text { Haematococcus pluvialis } \\
\text { (Bölgesel izolasyon) }\end{array}$ & \\
\hline
\end{tabular}

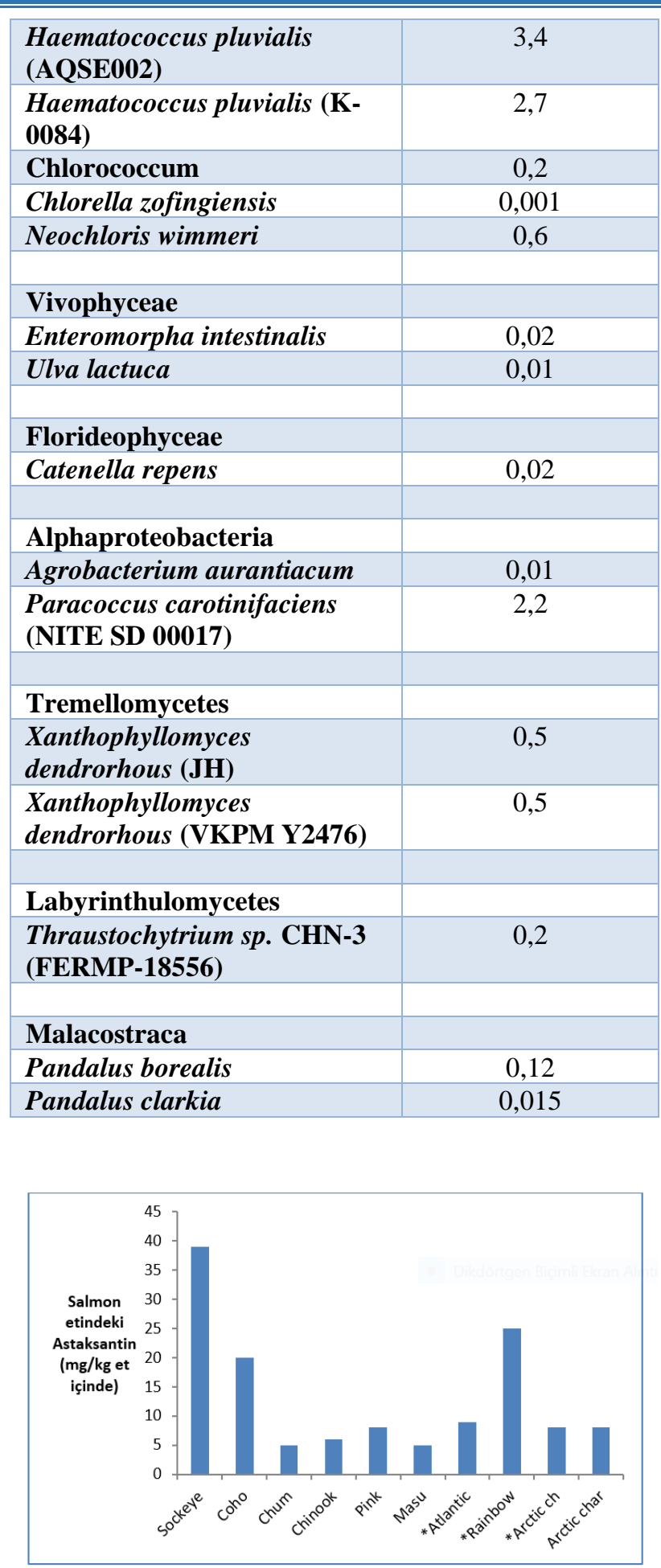

Doğal ve Yetiştirimiş Salmonlar

Şekil 2. Doğadaki ve çiftlikteki(*) salmonların Astaksantin seviyeleri (mg/kg et) (EFSA, 2005).

\section{ASTAKSANTIN'IN BIYYOSENTEZİ}

Astaksantin, su ürünleri yetiştiriciliğinde pigment olarak kullanılan bir ksantofildir. Alltrans izomeri doğada az miktarda 9-cis ve 13-cis izomerleri ile birlikte bulunur (Visser vd., 2005). Ekinenon ve kantaksantin yoluyla $\beta$-karotenlerin 
oluşum şeması, alg, maya ve fotosentetik olmayan bakterilerde iyi karakterize edilir (Fraser vd., 1997; Brittan, 1998). Bakterilerde, alglerde ve mayalarda astaksantin oluşumu için olası biyosentetik yollar Şekil 3'te gösterilmektedir (Bhosale ve Bernstein, 2005).

Mikroorganizmalar kullanılarak karotenoidlerin ticari üretimi, kırmızı maya olan $X$. dendrorhous kullanılarak fermantasyon yoluyla veya $H$. pluvialis algi açık havuzlarda kültürle üretilerek elde edilir (Jabobson vd., 2000; Lorenz ve Cysewski, 2000; Olaizola, 2000).

Transkript seviyeleri ile karotenoid biyosentezi arasında doğrusal bir ilişki bulunmamasına rağmen, $\beta$-karoten sentezinin basamaklarında yer alan astaksantin biyosentetik crtE, crtl ve crtYB genleri, $X$. dendrorhous'tan klonlanmıştır (Lodato vd., 2004).

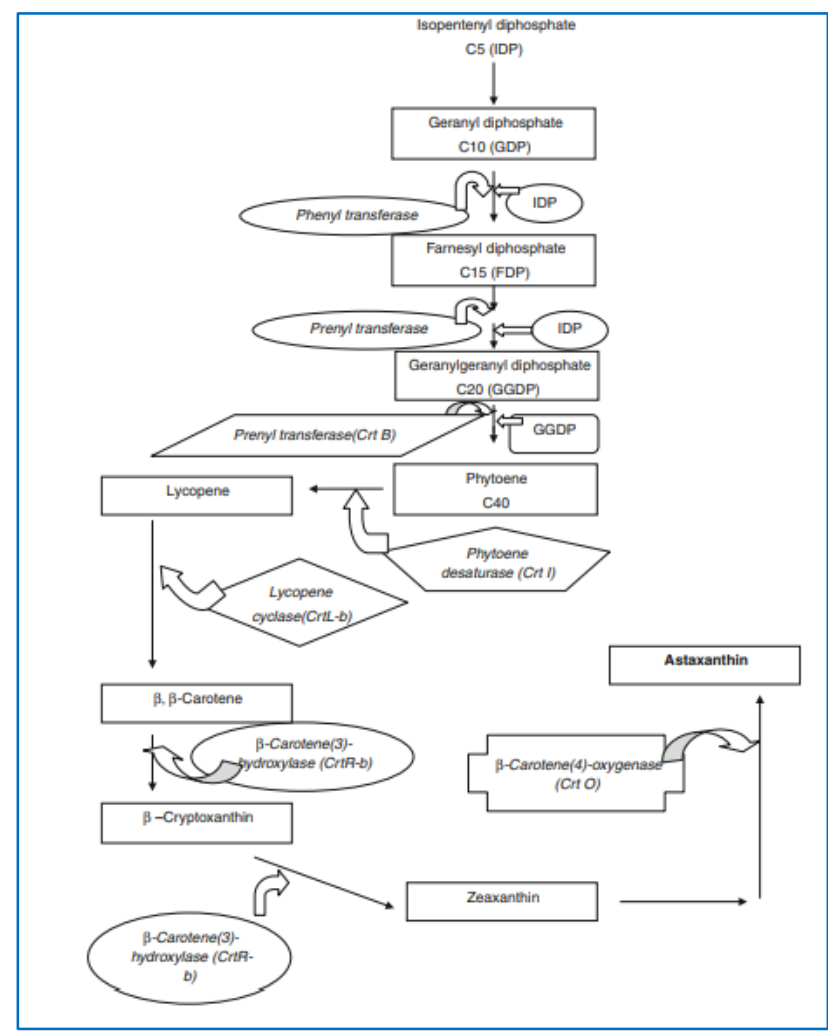

Şekil 3. Potansiyel mikroplar tarafından doğal gıda renklendiricisi olarak astaksantin üretimi (Adapted from Dufosse 2006)
ASTAKSANTIN'IN BIYYOSENTEZİ

Astaksantinin antioksidan aktivitesi

Bir antioksidan, oksidasyonu engelleyebilen bir moleküldür. Oksidatif hasar, serbest radikaller ve reaktif oksijen türleri (ROS) tarafindan başlatılır. Çok yüksek reaktiviteye sahip olan bu moleküller, organizmalarda normal aerobik metabolizma tarafından üretilmektedir. Fazla oksidatif moleküller, zincirleme reaksiyon yoluyla proteinler, lipidler ve DNA ile reaksiyona girerek protein ve lipid oksidasyonuna ve çeşitli bozukluklarla ilişkili DNA hasarına neden olabilmektedir. Bu tip oksidatif moleküller, karotenoidler gibi endojen ve eksojen antioksidanlar tarafından inhibe edilebilmektedir. Karotenoidler, zincir reaksiyonlarını sonlandırmak için singlet oksijeni söndürerek ve radikalleri temizleyerek antioksidan aktiviteler gerçekleştiren polien zinciri, uzun konjuge çift bağlar içermektedir. Karotenoidlerin biyolojik faydaları, hücre membranları ile fiziksel ve kimyasal etkileşimlerine atfedilen antioksidan özelliklerinden kaynaklandığı düşünülmektedir. Naguib vd., (2000) lutein, likopen, $\alpha$-karoten ve $\beta$-karoten gibi çeşitli karotenoidlerle karşılaştırıldığında astaksantin daha yüksek antioksidan aktiviteye sahip olduğunu bildirmişlerdir (Naguib 2000). Astaksantin kaynağ1 olan Haematococcus biyokütlesiyle beslenen sıçanların plazma ve karaciğerinde antioksidan enzimlerden katalaz, süperoksit dismutaz, peroksidaz ve tiyobarbütürik asit reaktif maddeleri yüksek olarak bulunmuştur (Ranga Rao vd., 2010). Haematococcus pluvialis'ten sağlanan Astaksantin, sıçanlarda serbest radikallere karşı, $\beta$-karoten ve luteinin ardından en iyi korumayı sağlamaktadır (Ranga Rao vd., 2010; Ranga Rao vd., 2013). Astaksantin, yüksek antioksidan özelliklerden sorumlu olan her iyonon halkasında hidroksil ve keto parçalarının varlığında benzersiz bir moleküler yapı içermektedir (Hussein vd., 2006; Liu vd., 2007). Astaksantinin antioksidan aktivitesi, zeaksantin, lutein, kantaksantin ve $\beta$ - 
karotenden 10 kat daha fazla; $\alpha$-tokoferolden 100 kat daha yüksek olarak bulunmuştur (Miki 1991). Karotenoidlerdeki okso fonksiyonel grup, pro-oksidatif katkı olmaksızın daha yüksek antioksidan aktiviteye sahiptir (Martin vd., 1999). Astaksantindeki polien zinciri, hücre zarındaki radikalleri yakalarken, astaksantinin terminal halkası, hücre zarının dış ve iç kısımlarındaki radikalleri temizleyebilmektedir (Şekil 3). Astaksantin tavşanların diyetine eklendikten sonra serumda antioksidan enzim aktiviteleri değerlendirilmiş, süperoksit dismutaz ve tioredoksin redüktaz aktivitesi artmış, oksidatifle indüklenen tavşanlarda paraoksonaz inhibe edilmiştir (Augusti vd., 2012). Astaksantin, etanol kaynaklı mide ülseri bulunan sıçanlara verildiğinde antioksidan enzim seviyeleri artmıştır (Kamath vd., 2008).

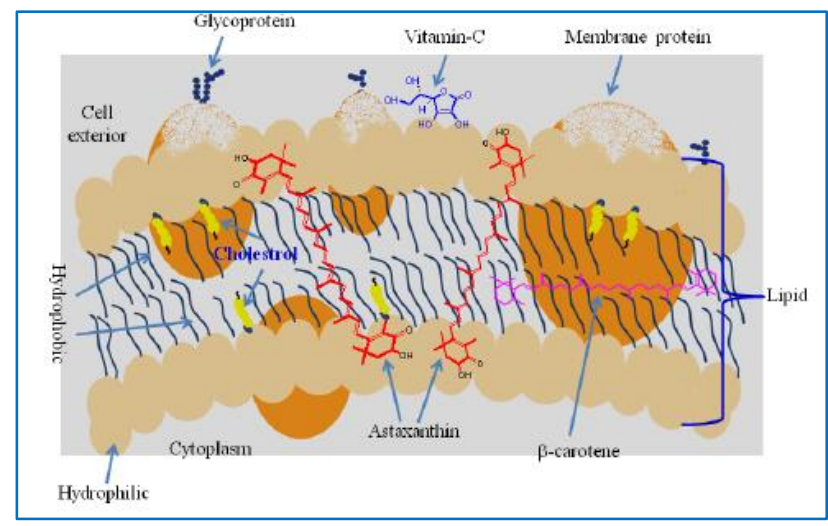

Şekil 4. Astaksantinin Hücre Zarı Üzerindeki Konumu (Ranga Rao vd., 2014)

\section{Anti-lipid peroksidasyon aktivitesi}

Astaksantin, hücre zarının hem içinde hem de dışında kalmasını sağlayan benzersiz bir moleküler yapıya sahiptir. Lipid çift tabakanın içine yerleştirilebilen $\beta$-karoten ve $C$ vitamininden daha iyi koruma sağlamaktadır. Zincirleme reaksiyonları önlemek için radikallerin temizlenmesi; lipid peroksidasyonunu inhibe ederek membran yapısının korunması; bağışıklık sistemi işlevinin geliştirilmesi gibi çeşitli mekanizmalarla oksidatif hasara karşı bir koruma görevi görmektedir. Astaksantin ve esterleri etanol kaynaklı mide ülseri bulunan sıçanlarda ve cilt kanseri olan sıçanlarda \%80 oranında anti lipid peroksidasyon aktivitesi göstermiştir (Kamath vd., 2008; Ranga Rao vd., 2013). Astaksantinin biyolojik örneklerdeki lipid peroksidasyonunu inhibe ettiği çeşitli araştırmacılar tarafindan bildirilmiştir (Goto vd., 2001; Kamath vd., 2008; Ranga Rao vd., 2009; Ranga Rao vd., 2010; Ranga Rao vd., 2013; Ranga Rao vd., 2013).

\section{Anti-inflamatuar aktivitesi}

Astaksantin, biyolojik sistemlerde iltihaplanmayı sona erdirmek için güçlü bir antioksidandır. Haematococcus ve Chlorococcum'un alg hücresi özleri, H. pylori ile enfekte farelerde bakteri yükünü ve mide iltihabını önemli ölçüde azaltmıştır (Bennedsen vd., 1999; Liu vd., 2003; Ranga Rao vd., 2010). Park vd.,, (2010) astaksantinin DNA oksidatif hasarını azalttığını böylece genç, sağlıklı, yetişkin dişi insan deneklerde bağışıklık tepkisinin arttığını bildirmişlerdir (Park vd., 2010). Başka bir çalışma, astaksantin esterlerinin ve Haematococcus kaynaklı toplam karotenoidlerin, siçanlarda etanolün neden olduğu mide ülserlerindeki akut, mide lezyonları üzerinde doza bağlı bir mide koruyucu etki gösterdiğini göstermiştir. Bu, H1, K1 ATPase inhibisyonu, müsin içeriğinin regülasyon artış1 ve antioksidan aktivitelerindeki artışa bağlanmaktadır (Kamath vd., 2008). Astaksantin, proksimal tübüler epitel hücrelerinde yüksek glukoz kaynaklı oksidatif stres, inflamasyon ve apoptoz üzerinde koruyucu etki göstermiştir. Japon araştırmacılar tarafından bildirildiği üzere Astaksantin, gözlerdeki oküler iltihaplanmanın tedavisi için umut verici bir moleküldür (Ohgami ve ark. 2003; Suzuki vd., 2006). Astaksantin, cildin kalınlaşmasını önleyebilir ve UV kaynaklı cilt hasarına karşı kolajen azalmasını azaltabilmektedir (Santos vd., 2012; Hama vd., 2012; Ranga Rao vd., 2013).

\section{Anti-diyabetik aktivitesi}

Diabetes mellittus hastalarında oksidatif stres seviyeleri genellikle çok yüksektir. Hastaların pankreasındaki $\beta$ hücrelerinin disfonksiyonu ve 
doku hasarına bağlı olarak hiperglisemi indüklenmektedir. Astaksantin, pankreas $\beta$ hücrelerinde hipergliseminin neden olduğu oksidatif stresi azaltabilmekte ve ayrıca glikoz ve serum insülin seviyelerini iyileştirebilmektedir (Uchiyama vd., 2002). Astaksantin, pankreas $\beta$ hücrelerini glikoz toksisitesine karşı koruyabilmektedir. Ayrıca, diyabetik sıçanlarla lenfosit işlev bozukluklarının iyileștirilmesinde iyi bir immünolojik ajan olduğu da gösterilmiştir (Otton vd., 2010). Aynı zamanda, lipid/protein oksidasyonunu önleyerek insan umbilikal ven endotel hücrelerinde glikasyon ve glikolize protein kaynaklı sitotoksisiteyi inhibe etmektedir (Nishigaki vd., 2010). Astaksantin ile tedavi edilen diyabetik farelerde idrar albümin seviyesi kontrol grubundan önemli ölçüde daha düşük olarak bulunmuştur (Uchiyama vd., 2002). Bazı çalışmalar, astaksantinin oksidatif stresi ve böbrek hücresi hasarını azaltarak diyabetik nefropatiyi önlediğini göstermiştir (Naito vd., 2004; Manabe vd., 2008).

\section{Kardiyovasküler aktivitesi}

Astaksantin, etkisi hem deney hayvanlarında hem de insan deneklerde incelenmiş antiinflamatuar etkiye sahip güçlü bir antioksidandır. Oksidatif stres ve inflamasyon, aterosklerotik kardiyovasküler hastalıkların patofizyolojik özellikleridir. Astaksantin, aterosklerotik kardiyovasküler hastalığa karşı potansiyel bir terapötik ajandır (Fassert vd., 2011). Hayvanlarda mikokardiyal iskemi reperfüzyon modeli kullanılarak mikokardiyumun korunmasında disodyum disüksinat astaksantinin (DDA) etkinliği değerlendirilmiştir. Miyokard infarkt boyutu Sprague Dawley sıçanlarında azaltılmış ve 25, 50 ve $75 \mathrm{mg} / \mathrm{kg}$ vücut ağırlığında DDA ile dört gün ön tedaviden sonra tavşanlarda miyokardiyal iyileşme gözlenmiştir (Gross vd., 2005; Lauver vd., 2005). Astaksantin, yedi gün boyunca 150 ve $500 \mathrm{mg} / \mathrm{kg}$ / gün dozunda DDA ile ön işlem yapılan sıçan miyokard dokularında bulunmuştur (Gross vd., 2006). Astaksantinin spontan hipertansif siçanlarda (SHR), normotansif Wistar Kyoto siçanlarda (NWKR) ve kendiliğinden hipertansif sıçanlarda (SPSHR) kan basıncı üzerindeki etkileri bildirilmiştir (Monroy-Ruiz vd., 2011). Astaksantin türevi ile beslenen farelerde plazma, kalp, karaciğer, trombositler ve artan bazal arter kan akışında astaksantin bulunmuştur (Khan vd., 2010). Astaksantin ile tedavi edilen insan umbilikal vien endotel hücreleri ve trombositleri, nitrik oksit seviyeleri artmış ve peroksinitrit seviyelerinde azalma göstermiştir (Khan vd., 2010). Yapılan bir çalışmada $\% 0.08$ astaksantin ile beslenen fareler, kontrol grubuna kıyasla daha yüksek kalp mitokondriyal membran potansiyeline ve kasılma indeksine sahip olduğu bulunmuştur (Nakao vd., 2010).

\section{Antikanser aktivitesi}

Spesifik antioksidan dozu, çeşitli dejeneratif bozuklukların erken teşhisi için yardımcı olabilmektedir. Normal aerobik metabolizmada süperoksit, hidrojen peroksit ve hidroksil radikali gibi reaktif oksijen türleri üretilmektedir. Singlet oksijen, fotokimyasal olaylarla üretilirken, peroksil radikalleri lipid peroksidasyonu ile üretilmektedir. $\mathrm{Bu}$ oksidanlar, DNA, proteinler ve lipidlerin oksidasyonu yoluyla yaşlanma, kanser ve ateroskleroz gibi dejeneratif hastalıklara neden olabilmektedir (Ryu vd., 2012). Antioksidan bileşikler, hücrelerde oksidatif hasarı inhibe ederek mutagenezi ve karsinogenezi azaltır. İnsan tümörlerinde boşluk bağlantıları yoluyla eksik olan hücre-hücre iletişimi ve restorasyonu tümör hücresi çoğalımını azaltma eğilimindedir. Boşluk bağlantı iletişimi, connexin-43 geninin yukar1 regülasyonu yoluyla connexin-43 proteinindeki bir artış nedeniyle oluşmaktadır. Doğal karotenoidler ve retinoidler ile hücreler arasında geçit iletişimi geliştirmiştir (Wolf 1992). Kantaksantin ve astaksantin türevleri, fare embriyosunun fibroblastları arasındaki geçit iletişimini geliştirmektedir (Hanusch vd., 1995; Daubrawa vd., 2005). $\beta$-karoten kullanımıyla murin fibroblast hücrelerinde artmış Connexin- 
43 ekspresyonu bildirilmektedir (Zhang vd., 1991; Zhang vd., 1992). Astaksantin; kantaksantin ve $\beta$-karoten gibi diğer karotenoidlerle karşılaştırıldığında önemli düzeyde antitümör aktivitesi göstermektedir (Chew vd., 1999; Chew vd., 2004). Astaksantin ayrica fibrosarkom, meme ve prostat kanseri hücrelerinin ve embriyonik fibroblastların büyümesini de inhibe etmiştir (Palozza vd., 2009). Astaksantin, kimyasal olarak indüklenmiş erkek/diși sıçanlarda ve farelerde hücre ölümünü, hücre çoğalmasını ve meme tümörlerini inhibe etmiştir (Tanaka vd., 1994; Tanaka vd.,1995; Jyonouchi vd., 2000; Prabhu vd., 2009; Nakao vd., 2010). H. pluvialis özütünün, hücre döngüsü ilerlemesini durdurduğu ve apoptozu teşvik ederek insan kolon kanseri hücrelerinin büyümesini inhibe ettiği Palozza ve diğerleri tarafından bildirilmiştir (Palozza vd., 2009). Nitro Astaksantin ve 15-nitrik astaksantin, peroksinitritli astaksantinin ürünleridir. 15nitroastaksantin antikanser özellikleri bir fare modelinde değerlendirilmiştir. Epstein-Barr virüsü ve fare derisi papillomlarındaki karsinojenez, astaksantin tedavisi ile önemli ölçüde inhibe edilmiştir (Maoka vd., 2012).

\section{İmmüno modülasyon}

Bağışıklık sistemi hücreleri, serbest radikal hasarına karşı çok hassastır. Hücre zarı, çoklu doymamış yă̆ asitleri (PUFA) içermektedir. Antioksidanlar, özellikle astaksantin, bağışıklık sistemi savunmasını korumak için serbest radikal hasarına karşı koruma sağlamaktadır. Astaksantinin laboratuar koşullarında hayvanlarda bağışıklık üzerindeki etkisi hakkında raporlar vardır, ancak insanlarda klinik araştırmalar eksiktir. Astaksantin, $\beta$-karotene kıyasla fare modelinde daha yüksek immünomodüle edici etkiler göstermiştir (Jyonouchi vd., 1991). Astaksantinli diyet takviyesinden sonra yaşlı hayvanlarda gelişmiş antikor üretimi ve azalmış humoral immün yanıt bildirilmiştir (Jyonouchi vd., 1991; Jyonouchi vd., 1994). Astaksantin, bir laboratuvar çalışmasında insan hücrelerinde immünoglobulinlerin üretimini teşvik etmiştir (Jyonouchi vd., 1995). İnsanlarda sekiz haftalık astaksantin takviyesi, kandaki astaksantin seviyelerinin artmasına ve virüslerle enfekte olmuş hücreleri hedef alan ve virüsleri yok eden doğal öldürücü hücrelerin aktivitesinin artmasına neden olmuştur (Park vd., 2010). Bu çalışmada astaksantin takviyeli grupta $\mathrm{T}$ ve $\mathrm{B}$ hücreleri artmış, DNA hasarı düşük ve C-reaktif protein (CRP) önemli ölçüde daha düşük bulunmuştur (Chew vd., 2004; Park vd., 2011; Augusti vd., 2012).

Astaksantinin biyolojik aktiviteleri ile ilgili son raporlar In vitro ve in vivo modellerde aşağıda sunulmuştur (Ranga Rao vd., 2014).

\section{Astaksantinin Biyolojik Aktiviteleri}

1. Antioksidan aktivite

2. UV ışınlarından koruma

3. Cilt kanserini önleyici

4. Anti-inflamatuvar

5. Mide hastalıklarına karşı aktivite

6. Kardiyovasküler hastalıkları önleyici

7. Bağışıklık tepkisi

8. Nöroproteksiyon

9. Anti- hepatoprotektif

10. Anti- diyabetik

\section{ASTAKSANTIININ GÜVENLİĞİ VE DOZU}

Astaksantin, gıda ile birlikte tüketildiğinde hiçbir yan etkisi olmaksızın güvenlidir. Sıçanlar astaksantin ile beslendikten sonra hayvan dokularında birikmiş ve toksik etkisi bulunmamıştır (Stewart vd., 2008; Ranga Rao vd., 2010; Ranga Rao vd., 2013). Aşırı astaksantin tüketimi, hayvanların derilerinde sarıdan kırmızıya dönen pigmentasyona yol açmaktadır. Astaksantin, balık yemine dahil edilerek balık derisinin kırmızımsı bir renk almasına neden olmaktadır. Astaksantinin oral dozajından sonra sıçanlarda süperoksit dismutaz, katalaz ve glutatyon peroksidaz seviyeleri gibi antioksidan enzimler önemli ölçüde artmıştır (Ranga Rao vd., 2013; Ranga Rao vd., 2013). Astaksantinin

supraterapötik 
konsantrasyonlarının trombosit, pıhtılaşma ve fibrinolitik fonksiyon üzerinde hiçbir yan etkisi bulunmamaktadır (Serebruany vd., 2010). Araştırmalar şimdiye kadar hayvanlarda ve insanlarda astaksantin tüketiminin önemli bir yan etkisi olmadığını bildirmiştir. Bu sonuçlar, gelecekteki klinik çalışmalar için astaksantinin güvenliğini desteklemektedir. Astaksantinin chia, keten tohumu, balık, findık, ceviz ve badem gibi omega-3 açısından zengin yağlı tohumlar ile uygulanması tavsiye edilmektedir.

Astaksantinin (4-8 mg) gidalarda, yumuşak jeller ve kapsüller ve krem şeklinde kombinasyonları piyasada mevcuttur. Önerilen günlük astaksantin dozu 2-4 mg / gün'dür. Bir çalışmada, yetişkin insanlarda astaksantin (6 $\mathrm{mg}$ /gün) uygulamasıyla hiçbir yan etkinin bulunmadığı bildirilmiștir (Spiller vd., 2003). Bir çalışmada, kan basıncının (bp) inme eğilimli sıçanlarda ve hipertansif sıçanlarda sırasıyla beş hafta ve 14 gün boyunca $50 \mathrm{mg} / \mathrm{kg}$ astaksantin ile beslenmesiyle azaldığı bildirmiştir (Hussein vd., 2005). Astaksantin ayrıca naproksen kaynaklı gastrit, antral ülsere karşı önemli bir koruma göstermiş ve mide mukozasında lipid peroksidasyon seviyelerini inhibe etmiştir (Kim vd.,2005; Augusti vd., 2012). Astaksantin farelere verildiğinde gözlerde astaksantin birikimi gözlemlenmiştir (Petri vd., 2007). Astaksantin biyoyararlanımı, lipit bazlı formülasyonların takviyesi ile artmıştır (Odeberg vd., 2003; Ranga Rao vd., 2010; Ranga Rao vd., 2013; Ranga Rao vd., 2013). Astaksantinin insan kan akışı üzerindeki etkileri, 10 gün boyunca $6 \mathrm{mg} /$ gün astaksantin uygulamasından sonra single-blind yöntemiyle yetişkin erkeklerde araştırılmıştır (Miyawaki vd., 2008). İnsan sağlı̆̆ına yararları üzerindeki astaksantinin dozaj etkilerine ilişkin son çalışmalar Tablo 2'te sunulmuştur.

Tablo 2. İnsan deneklerinde astaksantinin sağlık yararları (Ranga Rao vd., 2014).

\begin{tabular}{|c|c|c|c|}
\hline Deney Süresi & $\begin{array}{l}\text { Insanlarda } \\
\text { Konular }\end{array}$ & Doz (mg / gün) & Astaksantinin Faydaları \\
\hline 2 hafta & Gönüllüler & $\begin{array}{c}1.8,3.6,14.4 \mathrm{ve} \\
21.6\end{array}$ & LDL oksidasyonunun azaltılması \\
\hline Tek doz & $\begin{array}{l}\text { Orta yaşlı erkek } \\
\text { gönüllüler }\end{array}$ & 100 & $\begin{array}{l}\text { Astaksantin, VLDL kilomikronlar } \\
\text { tarafından ele alınır }\end{array}$ \\
\hline 8 hafta & Sağlıklı dişiler & 0.2 ve 8 & $\begin{array}{c}\text { Azalmış plazma 8-hidroksi-2'- } \\
\text { deoksiguanozin ve CRP seviyelerinde } \\
\text { düşürülmüştür }\end{array}$ \\
\hline 8 hafta & Sağlıklı yetişkinler & 6 & Kan basıncı ile değerlendirildi \\
\hline 10 gün & Sağlıklı erkekler & 6 & Geliştirilmiş kan reolojisi \\
\hline 12 hafta & $\begin{array}{l}\text { Sağlıklı, sigara } \\
\text { içmeyen Finli } \\
\text { erkekler }\end{array}$ & 8 & Yağ asitlerinin oksidasyonunda azalma \\
\hline 12 ay & $\begin{array}{l}\text { Yaşa bağlı makula } \\
\text { dejenerasyonu }\end{array}$ & 4 & $\begin{array}{l}\text { Yaşa bağlı makula dejenerasyonunda } \\
\text { gelişmiş merkezi retina disfonksiyonu }\end{array}$ \\
\hline 12 hafta & Orta yaşlı / yaşlı & 12 & Geliştirilmiş Cog sağlığı pil puanları \\
\hline 12 hafta & Orta yaşlı / yaşlı & 6 & $\begin{array}{c}\text { Groton labirent öğrenme testi puanları } \\
\text { iyileştirildi }\end{array}$ \\
\hline 8 veya 6 hafta & $\begin{array}{l}\text { Sağlıklı kadın veya } \\
\text { erkek }\end{array}$ & 6 & $\begin{array}{l}\text { Geliştirilmiş cilt kırışıklığı, korneosit } \\
\text { tabakası, epidermis ve dermis }\end{array}$ \\
\hline 2 hafta & $\begin{array}{l}\text { Hastalık (iki taraflı } \\
\text { katarakt) }\end{array}$ & 6 & $\begin{array}{l}\text { İnsan gözyaşı salgısında gelişmiş } \\
\text { süperoksit temizleme aktivitesi sağlar ve } \\
\text { hidroperoksitleri düşürür. }\end{array}$ \\
\hline
\end{tabular}

LDL, Düşük yoğunluklu lipoproteinler, VLDL, Çok düşük yoğunluklu lipoprotein, CRP, C-reaktif protein.

\section{ASTAKSANTIINIIN GÜVENLIIĞİ VE DOZU}

Doğal kaynaklardan astaksantin üretimi, biyoteknolojideki en başarılı faaliyetlerden biri haline gelmiştir. Astaksantin gıda, yem, nutrasötik ve farmasötik uygulamalarında büyük talep görmektedir. Bu durum, sentetik kaynaklar yerine biyolojik kaynaklardan astaksantin üretimini geliştirmeye yönelik büyük çabaları 
teşvik etmektedir. Güncel literatüre göre, astaksantin piyasadaki çeşitli ticari uygulamalarda kullanılmaktadır. Astaksantin ürünleri piyasada kapsül, yumuşak jel, tablet, toz, biyokütle, krem, enerji içeceği, yağ ve öz şeklinde mevcuttur (Tablo 3). Astaksantin ürünlerinin bir kısmı diğer karotenoidler, multivitaminler, bitkisel özler ve omega-3,6 yă̆ asitleri ile kombinasyon yapılmıştır. Bakteriyel enfeksiyon, iltihaplanma, damar hastalıkları, kanser, kardiyovasküler hastalıkları önlemek, lipid peroksidasyonunu engellemek, hücre hasarını ve vücut yağını azaltmak ve beyin fonksiyonunu ve cilt hastalıklarını iyileştirmek için astaksantin üzerine patent başvuruları mevcuttur (Tablo 4).

Tablo 3. Çeşitli Ticari firmaların Astaksantin ürünleri ve çeşitli amaçlarla kullanımı.

\begin{tabular}{|c|c|c|c|c|}
\hline Marka adı & Dozaj formu & Malzemeler & Şirket Adı & Amaç \\
\hline $\begin{array}{l}\text { Physician } \\
\text { Formulas }\end{array}$ & $\begin{array}{c}\text { Yumuşak jel / } \\
\text { Tabletler }\end{array}$ & $2 \mathrm{mg} / 4 \mathrm{mg}-\mathrm{AX}$ & $\begin{array}{l}\text { Hekim formülleri } \\
\text { vitamin şirketi }\end{array}$ & Antioksidan \\
\hline Eyesight Rx & Tablet & $\begin{array}{l}\text { AX, C vitamini, } \\
\text { bitki özleri }\end{array}$ & $\begin{array}{l}\text { Hekim formülleri } \\
\text { Vitamin şirketi }\end{array}$ & Görme işlevi \\
\hline KriaXanthin & Yumuşak jel & $\begin{array}{c}1,5 \mathrm{mg}-\mathrm{AX}, \mathrm{EPA}, \\
\text { DHA }\end{array}$ & $\begin{array}{l}\text { Hekim formülleri } \\
\text { vitamin şirketi }\end{array}$ & Antioksidan \\
\hline Astaksantin Ultra & Yumuşak jel & $4 \mathrm{mg}-\mathrm{AX}$ & AOR & $\begin{array}{c}\text { Kardiyovasküler } \\
\text { sağlık / } \\
\text { gastrointestinal }\end{array}$ \\
\hline $\begin{array}{l}\text { Astaxanthin Gold } \\
\text { TM }\end{array}$ & Yumuşak jel & $4 \mathrm{mg}-\mathrm{AX}$ & Nutrigold & $\begin{array}{l}\text { Göz / eklem / cilt / } \\
\text { bağıșıklık sağlığı }\end{array}$ \\
\hline Best Astaxanthin & $\begin{array}{c}\mathrm{Y} \\
\text { umuşak jel }\end{array}$ & $6 \mathrm{mg}-\mathrm{AX}, \mathrm{CX}$ & Bioastin & $\begin{array}{c}\text { Hücre zarı / kan } \\
\text { akışı }\end{array}$ \\
\hline Dr Mercola & Kapsüller & $\begin{array}{c}4 \mathrm{mg} \mathrm{AX}, 325 \mathrm{mg} \\
\text { Omega-3 ALA }\end{array}$ & $\begin{array}{c}\text { Dr.Mercola } \\
\text { premium takviyeleri }\end{array}$ & Yaşlanma / kas \\
\hline Solgar & Yumuşak jel & $5 \mathrm{mg}-\mathrm{AX}$ & $\begin{array}{l}\text { Solgar global } \\
\text { üretimi }\end{array}$ & Sağlıklı cilt \\
\hline Astaksantin & Krem & AX, bitkisel özler & True botanica & Yüz nemlendirme \\
\hline astavita ex & Kapsüller & 8 mg AX, T3 & $\begin{array}{c}\text { Fuji Kimya } \\
\text { Endüstrisi }\end{array}$ & $\begin{array}{c}\text { Yaşlanma karşıtı } \\
\text { bakım }\end{array}$ \\
\hline astavita SPOR & Kapsüller & $\begin{array}{l}9 \text { mg AX, T3 ve } \\
\text { çinko }\end{array}$ & $\begin{array}{l}\text { Fuji Kimya } \\
\text { Endüstrisi }\end{array}$ & Spor Beslenmesi \\
\hline AstaTROL & Yağ & $\mathrm{AX}$ & $\begin{array}{c}\text { Fuji Kimya } \\
\text { Endüstrisi }\end{array}$ & $\begin{array}{c}\text { Makyaj } \\
\text { malzemeleri }\end{array}$ \\
\hline AstaFX & Kapsüller & $\mathrm{AX}$ & $\begin{array}{c}\text { Saflık ve ürün } \\
\text { kanıta dayalı besin } \\
\text { takviyeleri }\end{array}$ & $\begin{array}{c}\text { Deri / } \\
\text { kardiyovasküler } \\
\text { fonksiyon }\end{array}$ \\
\hline $\begin{array}{l}\text { Pure } \\
\text { Encapsulations }\end{array}$ & Kapsüller & $\mathrm{AX}$ & Sinerjik beslenme & Antioksidan \\
\hline Zanthin Xp-3 & $\begin{array}{l}\text { Yumuşak jel } \\
\text { kapsüller }\end{array}$ & $2 \mathrm{mg}, 4 \mathrm{mg}-\mathrm{AX}$ & Valensa & İnsan vücudu \\
\hline $\begin{array}{l}\text { Micro Algae Super } \\
\text { Food }\end{array}$ & Yumuşak jel & $4 \mathrm{mg} A X$ & $\begin{array}{l}\text { Anumed intel } \\
\text { biomed şirketi }\end{array}$ & Kalp / göz / eklem \\
\hline
\end{tabular}

AX, astaksantin, AX, astaksantin esterleri, CX, kantaksantin, DHA, dokosaheksaenoik asit, EPA, eikosapentaenoik asit, ALA, alfa linolenik asit, T3, tokotrienol.

\section{SONUC}

Astaksantin ile ilgili in vitro ve in vivo modellerde mevcut araştırma verileri cesaret vericidir. Astaksantin, kanserler, hipertansiyon, diyabet, kardiyovasküler, gastrointestinal, karaciğer, nörodejeneratif ve cilt hastalıkları gibi çeşitli hastalıklar üzerinde potansiyel etkiler göstermiştir. Antioksidan özelliği, hastalıklı hücrelerde oksidatif hasara karşı kullanılmaktadır. Bununla birlikte, astaksantin 
esterleri (mono-di) ve biyolojik sistemlerdeki metabolik yolları hakkında araştırma eksikliği vardır. Gelecekteki araştırmalar, astaksantin esterlerinin çeşitli biyolojik aktiviteler üzerindeki etkilerine ve bunların nutrasötik ve farmasötik uygulamalardaki kullanımlarına odaklanmalıdır. Astaksantin mono-diesterler, biyolojik aktiviteleri metabolizma tarafindan kolayca emilebilen serbest formdan daha iyi artırabilir. Daha fazla araştırma, metabolik yollarının araştırılmasını ve ayrıca ticari amaçlarla kullanımları için in vitro ve in vivo modellerde moleküler çalışmaların araştırılmasını gerektirmektedir.

Tablo 4. Astaksantin için son patent başvuruları (Ranga Rao vd., 2014).

\begin{tabular}{|c|c|c|}
\hline Patent No & Başlık & Amaç \\
\hline US2006021744 & $\begin{array}{c}\text { Doğal astaksantin özü, DNA } \\
\text { oksidasyonunu azaltır }\end{array}$ & Endojen oksidatif hasarı azaltır. \\
\hline US20070293568 & Nörosit koruyucu ajan & Nöroproteksiyon \\
\hline US20080234521 & Astaksantinin kristal formları & Besin dozu \\
\hline US20080293679 & $\begin{array}{c}\text { COX inhibitörlerinin belirli } \\
\text { olumsuz etkilerinin azaltılması / } \\
\text { inhibisyonu için karotenoidlerin ve } \\
\text { karotenoid türevleri analoglarının } \\
\text { kullanımı }\end{array}$ & $\begin{array}{l}\text { Lipid peroksidasyonunu inhibe } \\
\text { eder. }\end{array}$ \\
\hline US20090047304 & Vücut yağı azaltma bileşimi & Vücut yağlanmasını engeller. \\
\hline US20090069417 & $\begin{array}{c}\text { Kemopreventif ve kemoterapötik } \\
\text { ajanlar olarak karotenoid } \\
\text { oksidasyon ürünleri }\end{array}$ & Kanseri önleme \\
\hline US20090136469 & $\begin{array}{l}\text { Kardiyovasküler sistem üzerinde } \\
\text { yararlı etkileri olan oral uygulama } \\
\text { için formülasyon }\end{array}$ & Kardiyovasküler koruma \\
\hline US20090142431 & $\begin{array}{c}\text { Alg ve yosun özü diyet takviyesi } \\
\text { bileşimi }\end{array}$ & Diyet takviyesi \\
\hline US20090297492 & $\begin{array}{c}\text { Bilişsel performansı iyileştirme } \\
\text { yöntemi }\end{array}$ & Beyin işlevini iyileştirmek \\
\hline US20100204523 & $\begin{array}{l}\text { Karotenoid pigmentin ve bunun } \\
\text { için kullanılan kabın renginin } \\
\text { solmasını önleme yöntemi }\end{array}$ & Renk değişiminin önlenmesi \\
\hline US20100267838 & $\begin{array}{l}\text { İceceklerin renklendirilmesi için } \\
\text { toz halinde karotenoid hazırlama }\end{array}$ & İçecekler \\
\hline US20100291053 & İnflamatuar hastalıkların tedavisi & İnflamatuar hastalığ önleme \\
\hline US20120004297 & $\begin{array}{c}\text { Vasküler yetmezliği hafifletmek } \\
\text { için ajan }\end{array}$ & Vasküler yetmezliğin önlenmesi \\
\hline US20120114823 & $\begin{array}{c}\text { Geliştirilmiş pigment tutma için } \\
\text { yem katkı maddesi }\end{array}$ & Balık yemi \\
\hline US20120238522 & $\begin{array}{c}\text { Karotenoid içeren bileşimler ve } \\
\text { yöntemler }\end{array}$ & $\begin{array}{l}\text { Bakteriyel enfeksiyonların } \\
\text { önlenmesi }\end{array}$ \\
\hline US20120253078 & $\begin{array}{c}\text { Domuz yetiştiriciliğinde karkas } \\
\text { performansını iyileştirmek için ajan }\end{array}$ & Besin takviyeleri \\
\hline US20130004582 & $\begin{array}{l}\text { Eklem ağrısını hafifletmek için } \\
\text { bileşim ve yöntem }\end{array}$ & $\begin{array}{l}\text { Azaltılmış eklem ağrısı ve } \\
\text { osteoartrit semptomları }\end{array}$ \\
\hline US20130108764 & $\begin{array}{l}\text { Astaksantin içeren hamurdan } \\
\text { üretilen pişmiş yiyecekler }\end{array}$ & $\begin{array}{l}\text { Pişmiş yiyeceklerde kullanılan } \\
\text { astaksantin }\end{array}$ \\
\hline
\end{tabular}

\section{AÇIKLAMALAR}

Çıkar çatışması: Yazar, bu makale için gerçek, potansiyel veya algılanan bir çıkar çatışması olmadığını beyan etmektedirler. 


\section{KAYNAKLAR}

Ambati, R. R., Phang, S. M., Ravi, S., \& Aswathanarayana, R. G. (2014). Astaxanthin: sources, extraction, stability, biological activities and its commercial applications - a review. Marine drugs, 12(1), 128-152.

Augusti, P. R., Quatrin, A., Somacal, S., Conterato, G. M., Sobieski, R., Ruviaro, A. R., ... \& Emanuelli, T. (2012). Astaxanthin prevents changes in the activities of thioredoxin reductase and paraoxonase in hypercholesterolemic rabbits. Journal of clinical biochemistry and nutrition, Volume 51 Issue 1 Pages 42-49.

Bhosale P, Bernstein PS (2005) Microbial xanthophylls. Appl Microbiol Biotechnol 68, 445-455.

Britton, G. (1998) Overview of carotenoid biosynthesis. Carotenoids, 3, 13-147.

Catanzaro, E., Bishayee, A., \& Fimognari, C. (2020). On a beam of light: Photoprotective activities of the marine carotenoids astaxanthin and fucoxanthin in suppression of inflammation and cancer. Marine Drugs, 18(11), 544.

Chew, B. P., Park, J. S., Wong, M. W., \& Wong, T. S. (1999). A comparison of the anticancer activities of dietary beta-carotene, canthaxanthin and astaxanthin in mice in vivo. Anticancer research, 19(3A), 1849-1853.

Chew, B. P., \& Park, J. S. (2004). Carotenoid action on the immune response. The Journal of nutrition, 134(1), 257S-261S.

Choi, S., \& Koo, S. (2005). Efficient syntheses of the keto-carotenoids canthaxanthin, astaxanthin, and astacene. The Journal of Organic Chemistry, 70(8), 3328-3331.

Daubrawa, F., Sies, H., \& Stahl, W. (2005). Astaxanthin diminishes gap junctional intercellular communication in primary human fibroblasts. The Journal of nutrition, 135(11), 2507-2511.

D'Orazio, N.; Gammone, M.A.; Gemello, E.; DeGirolamo, M.; Cusenza, S.; Riccioni, G. (2012). Marine bioactives: Pharmacological properties and potential applications against inflammatory diseases. Mar. Drugs, 10, 812-833.

Dufossé, L. (2006). Microbial production of food grade pigments. Food technology and Biotechnology, 44(3), 313-323.

EFSA (Avrupa Gıda Güvenliği Otoritesi) (2005). Hayvanların beslenmesinde renklendirici ajanların güvenliğine ilişkin Avrupa komisyonunun talebi üzerine, hayvan yemlerinde kullanılan katkı maddeleri ve ürünler veya maddeler hakkındaki bilimsel panel görüşü. EFSA J., 291, 1-40.

Fassett, R. G., \& Coombes, J. S. (2011). Astaxanthin: a potential therapeutic agent in cardiovascular disease. Marine drugs, 9(3), 447-465.

Fraser, P. D., Miura, Y., \& Misawa, N. (1997). In vitro characterization of astaxanthin biosynthetic enzymes. Journal of Biological Chemistry, 272(10), 6128-6135.

Gammone, M. A., Riccioni, G., \& D'Orazio, N. (2015). Marine carotenoids against oxidative stress: effects on human health. Marine Drugs, 13(10), 6226-6246.
Goto, S., Kogure, K., Abe, K., Kimata, Y., Kitahama, K., Yamashita, E., \& Terada, H. (2001). Efficient radical trapping at the surface and inside the phospholipid membrane is responsible for highly potent antiperoxidative activity of the carotenoid astaxanthin. Biochimica et biophysica acta (BBA)biomembranes, 1512(2), 251-258.

Hama, S., Takahashi, K., Inai, Y., Shiota, K., Sakamoto, R., Yamada, Tsuchiya,H., Kanamura,K., Yamashita,E., Kogure, K. (2012). Protective effects of topical application of a poorly soluble antioxidant astaxanthin liposomal formulation on ultravioletinduced skin damage. Journal of pharmaceutical sciences, 101(8), 2909-2916.

Hanusch, M., Stahl, W., Schulz, W. A., \& Sies, H. (1995). Induction of gap junctional communication by 4-oxoretinoic acid generated from its precursor canthaxanthin. Archives of biochemistry and biophysics, 317(2), 423-428.

Hussein, G., Nakamura, M., Zhao, Q., Iguchi, T., Goto, H., Sankawa, U., \& Watanabe, H. (2005). Antihypertensive and neuroprotective effects of astaxanthin in experimental animals. Biological and Pharmaceutical Bulletin, 28(1), 47-52.

Hussein, G., Sankawa, U., Goto, H., Matsumoto, K., \& Watanabe, H. (2006). Astaxanthin, a carotenoid with potential in human health and nutrition. Journal of natural products, 69(3), 443-449.

Iizuka, M., Ayaori, M., Uto-Kondo, H., Yakushiji, E., Takiguchi, S., Nakaya, K., ... \& Ikewaki, K. (2012). Astaxanthin enhances ATP-binding cassette transporter A1/G1 expressions and cholesterol efflux from macrophages. Journal of nutritional science and vitaminology, 58(2), 96-104.

Jacobson GK, Jolly SO, Sedmark JJ, Skatrud TJ, Wasileski JM (2000) Astaxanthin over-producing strains of Phaffia rhodozyma. Method for their cultivation and their use in animal feeds. US Patent $6,015,684$

Jyonouchi, H., Hill, R. J., Tomita, Y., \& Good, R. A. (1991). Studies of immunomodulating actions of carotenoids. I. Effects of $\beta$-carotene and astaxanthin on murine lymphocyte functions and cell surface marker expression in in vitro culture system . Nutrition and Cancer, 16: 93-105.

Jyonouchi, H., Zhang, L., Gross, M., \& Tomita, Y. (1994). Immunomodulating actions of carotenoids: enhancement of in vivo and in vitro antibody production to T-dependent antigens. Nutr Cancer. 21(1):47-58.

Jyonouchi, H., Sun, S., \& Gross, M. (1995). Effect of carotenoids on in vitro immunoglobulin production by human peripheral blood mononuclear cells: Astaxanthin, a carotenoid without vitamin a activity, enhances in vitro immunoglobulin production in response to at-dependent stimulant and antigen. Nutr Cancer. 23(2):171-183.

Jyonouchi, H., Sun, S., Iijima, K., \& Gross, M. D. (2000). Antitumor activity of astaxanthin and its mode of action. Nutrition and cancer, 36(1), 59-65. 
Katagiri, M., Satoh, A., Tsuji, S., \& Shirasawa, T. (2011). Effects of astaxanthin-rich Haematococcus pluvialis extract on cognitive function: a randomised, double-blind, placebo-controlled study. Journal of clinical biochemistry and nutrition, 12032701501203270150.

Khan, S. K., Malinski, T., Mason, R. P., Kubant, R., Jacob, R. F., Fujioka, K., ... \& Bodary, P. F. (2010). Novel astaxanthin prodrug (CDX-085) attenuates thrombosis in a mouse model. Thrombosis research, 126(4), 299-305.

Kim, J. H., Kim, Y. S., Song, G. G., Park, J. J., \& Chang, H. I. (2005). Protective effect of astaxanthin on naproxen-induced gastric antral ulceration in rats. European journal of pharmacology, 514(1), 53-59.

Krinsky, N. I. (1994). The biological properties of carotenoids. Pure and Applied Chemistry, 66(5), 10031010.

Lauver, D. A., Lockwood, S. F., \& Lucchesi, B. R. (2005). Disodium Disuccinate Astaxanthin (Cardax) attenuates complement activation and reduces myocardial injury following ischemia/ reperfusion. Journal of Pharmacology and Experimental Therapeutics, 314(2), 686-692.

Liu, B. H., \& Lee, Y. K. (2003). Effect of total secondary carotenoids extracts from Chlorococcum sp. on Helicobacter pylori-infected $\mathrm{BALB} / \mathrm{c}$ mice. Int. immunopharmacology, 3(7), 979-986.

Liu, X., \& Osawa, T. (2007). Cis astaxanthin and especially 9-cis astaxanthin exhibits a higher antioxidant activity in vitro compared to the all-trans isomer. Biochemical and biophysical research communications, 357(1), 187-193.Lockwood, S. F., \& Mason, R. P. (2008). U.S. Patent Application No. 11/417,307.

Lodato P, Alcaino J, Barahona S, Retamales P, Jimenez A, Cifuentes V (2004) Study of the expression of carotenoid biosynthesis genes in wildtype and deregulated strains of Xanthophyllomyces dendrorhous (Ex.: Phaffia rhodozyma). Biol Res, 37, 83-93

Lorenz, R. T. (1999). A technical review of Haematococcus algae. NatuRoseTM Technical Bulletin, 60, 1-12.

Lorenz, R. T., \& Cysewski, G. R. (2000). Commercial potential for Haematococcus microalgae as a natural source of astaxanthin. Trends in biotechnology, 18(4), 160-167.

Manabe, E., Handa, O., Naito, Y., Mizushima, K., Akagiri, S., Adachi, S., ... \& Yoshikawa, T. (2008). Astaxanthin protects mesangial cells from hyperglycemia-induced oxidative signaling. Journal of cellular biochemistry, 103(6), 1925-1937.

Maoka, T., Tokuda, H., Suzuki, N., Kato, H., \&amp; Etoh, H. (2012). Anti-oxidative, anti-tumorpromoting, and anti-carcinogensis activities of nitroastaxanthin and nitrolutein, the reaction products of astaxanthin and lutein with peroxynitrite. Marine drugs, 10(6), 1391-1399.

Martin, H. D., Jäger, C., Ruck, C., Schmidt, M., Walsh, R., \& Paust, J. (1999). Anti-and prooxidant properties of carotenoids. Journal für praktische Chemie, 341(3), 302-308
Miki, W. (1991). Biological functions and activities of animal carotenoids. Pure Appl. Chem, 63(1), 141-146.

Monroy-Ruiz, J., Sevilla, M. Á., Carrón, R., \& Montero, M. J. (2011). Astaxanthin-enriched-diet reduces blood pressure and improves cardiovascular parameters in spontaneously hypertensive rats. Pharmacological Research, 63(1), 44-50.

Naguib, Y. M. (2000). Antioxidant activities of astaxanthin and related carotenoids. Journal of agricultural and food chemistry, 48(4), 1150-1154.

Naito, Y., Uchiyama, K., Aoi, W., Hasegawa, G., Nakamura, N., Yoshida, N., ... \& Yoshikawa, T. (2004). Prevention of diabetic nephropathy by treatment with astaxanthin in diabetic $\mathrm{db} / \mathrm{db}$ mice. Biofactors, 20(1), 49-59.

Nakao, R., Nelson, O. L., Park, J. S., Mathison, B. D., Thompson, P. A., \& Chew, B. P. (2010). Effect of dietary astaxanthin at different stages of mammary tumor initiation in BALB/c mice. Anticancer research, 30(6), 2171-2175.

Nakao, R., Nelson, O. L., Park, J. S., Mathison, B. D., Thompson, P. A., \&amp; Chew, B. P. (2010). Effect of astaxanthin supplementation on inflammation and cardiac function in $\mathrm{BALB} / \mathrm{c}$ mice. Anticancer Research, 30(7), 2721-2725.

Nishigaki, I., Rajendran, P., Venugopal, R., Ekambaram, G., Sakthisekaran, D., \& Nishigaki, Y. (2010). Cytoprotective role of astaxanthin against glycated protein/iron chelate-induced toxicity in human umbilical vein endothelial cells. Phytotherapy Research: An International Journal Devoted to Pharmacological and Toxicological Evaluation of Natural Product Derivatives, 24(1), 54-59.

Odeberg, J. M., Lignell, Å., Pettersson, A., \& Höglund, P. (2003). Oral bioavailability of the antioxidant astaxanthin in humans is enhanced by incorporation of lipid based formulations. European journal of pharmaceutical sciences, 19(4), 299-304.

Ohgami, K., Shiratori, K., Kotake, S., Nishida, T., Mizuki, N., Yazawa, K., \& Ohno, S. (2003). Effects of astaxanthin on lipopolysaccharide-induced inflammation in vitro and in vivo. Investigative ophthalmology \& visual science, 44(6), 2694-2701.

Olaizola, M. (2000). Commercial production of astaxanthin from Haematococcus pluvialis using 25,000-liter outdoor photobioreactors. Journal of Applied Phycology, 12(3), 499-506.

Otton, R., Marin, D. P., Bolin, A. P., dos Santos, R. D. C. M., Polotow, T. G., Sampaio, S. C., \& de Barros, M. P. (2010). Astaxanthin ameliorates the redox imbalance in lymphocytes of experimental diabetic rats. Chemico-Biological Interactions, 186(3), 306315.

Palozza, P., Torelli, C., Boninsegna, A., Simone, R., Catalano, A., Mele, M. C., \& Picci, N. (2009). Growth-inhibitory effects of the astaxanthin-rich alga Haematococcus pluvialis in human colon cancer cells. Cancer letters, 283(1), 108-117.

Petri, D., \& Lundebye, A. K. (2007). Tissue distribution of astaxanthin in rats following exposure to graded levels in the feed. Comparative Biochemistry and Physiology Part C: Toxicology \& Pharmacology, 145(2), 202-209. 
Prabhu, P. N., Ashokkumar, P., \& Sudhandiran, G. (2009). Antioxidative and antiproliferative effects of astaxanthin during the initiation stages of 1, 2-dimethyl hydrazine-induced experimental colon carcinogenesis. Fundamental \& clinical pharmacology, 23(2), 225234.

Ranga, R., Sarada, A. R., Baskaran, V., \& Ravishankar, G. A. (2009). Identification of carotenoids from green alga Haematococcus pluvialis by HPLC and LC-MS (APCI) and their antioxidant properties. Journal of microbiology and biotechnology, 19(11), 1333-1341.

Ranga Rao, A., Raghunath Reddy, R. L., Baskaran, V., Sarada, R., \& Ravishankar, G. A. (2010). Characterization of microalgal carotenoids by mass spectrometry and their bioavailability and antioxidant properties elucidated in rat model. Journal of agricultural and food chemistry, 58(15), 8553-8559.

Ryu, S. K., King, T. J., Fujioka, K., Pattison, J., Pashkow, F. J., \& Tsimikas, S. (2012). Effect of an oral astaxanthin prodrug (CDX-085) on lipoprotein levels and progression of atherosclerosis in LDLR-/and ApoE-/- mice. Atherosclerosis, 222(1), 99-105.

Santos, S. D., Cahú, T. B., Firmino, G. O., de Castro, C. C., Carvalho Jr, L. B., Bezerra, R. S., \& Filho, J. L. L. (2012). Shrimp waste extract and astaxanthin: rat alveolar macrophage, oxidative stress and inflammation. Journal of Food Science, 77(7), H141H146.

Serebruany, V., Malinin, A., Goodin, T., \& Pashkow, F. (2010). The in vitro effects of Xancor, a synthetic astaxanthine derivative, on hemostatic biomarkers in aspirin-naive and aspirin-treated subjects with multiple risk factors for vascular disease. American $j$. of therapeutics, 17(2), 125-132.

Stewart, J. S., Lignell, Å., Pettersson, A., Elfving, E., \& Soni, M. G. (2008). Safety assessment of astaxanthinrich microalgae biomass: Acute and subchronic toxicity studies in rats. Food and Chemical Toxicology, 46(9), 3030-3036.

Suzuki, Y., Ohgami, K., Shiratori, K., Jin, X. H., Ilieva, I., Koyama, Y., ... \& Ohno, S. (2006). Suppressive effects of astaxanthin against rat endotoxin-induced uveitis by inhibiting the $\mathrm{NF}-\kappa \mathrm{B}$ signaling pathway. Experimental eye research, 82(2), 275-281.

Tanaka, T., Morishita, Y., Suzui, M., Kojima, T., Okumura, A., \& Mori, H. (1994). Chemoprevention of mouse urinary bladder carcinogenesis by the naturally occurring carotenoid astaxanthin. Carcinogenesis, 15(1), 15-19.

Tanaka, T., Makita, H., Ohnishi, M., Mori, H., Satoh, K., \& Hara, A. (1995). Chemoprevention of rat oral carcinogenesis by naturally occurring xanthophylls, astaxanthin and canthaxanthin. Cancer Research, 55(18), 4059-4064.

Uchiyama, K., Naito, Y., Hasegawa, G., Nakamura, N., Takahashi, J., \& Yoshikawa, T. (2002). Astaxanthin protects $\beta$-cells against glucose toxicity in diabetic db/db mice. Redox Report, 7(5), 290-293.

Visser, H., van Ooyen, A. J., \& Verdoes, J. C. (2003). Metabolic engineering of the astaxanthin-biosynthetic pathway of Xanthophyllomyces dendrorhous. FEMS yeast research, 4(3), 221-231.
Wolf, G. (1992). Retinoids and carotenoids as inhibitors of carcinogenesis and inducers of cell-cell communication. Nutrition reviews, 50(9), 270-274.

Zhang, L. X., Cooney, R. V., \& Bertram, J. S. (1991). Carotenoids enhance gap junctional communication and inhibit lipid peroxidation in $\mathrm{C} 3 \mathrm{H} / 10 \mathrm{~T} 1 / 2$ cells: relationship to their cancer chemopreventive action. Carcinogenesis, 12(11), 2109-2114.

Zhang, L. X., Cooney, R. V., \& Bertram, J. S. (1992). Carotenoids up-regulate connexin43 gene expression independent of their provitamin A or antioxidant properties. Cancer research, 52(20), 5707-5712. 